\title{
Total aortic repair: the new paradigm in the treatment of acute type A aortic dissection
}

\author{
George Matalanis ${ }^{1}$, Nisal K. Perera ${ }^{1}$, Sean D. Galvin ${ }^{2}$ \\ ${ }^{1}$ Department of Cardiac Surgery, The Austin Hospital, Heidelberg, Australia; ${ }^{2}$ Department of Cardiothoracic Surgery, Wellington Regional Hospital, \\ Wellington, New Zealand \\ Correspondence to: Professor George Matalanis. Director, Department of Cardiothoracic Surgery, The Austin Hospital, PO BOX 555, Heidelberg, \\ Victoria 3084, Australia. Email: george.matalanis@austin.org.au.
}

\begin{abstract}
The surgical management of acute type A aortic dissection (ATAAD) is in a period of rapid evolution. Understanding the complex physiology and anatomy of both acute and chronic dissection has been enhanced by the ready availability of state of the art imaging techniques. Technical advances in the intraoperative monitoring of organ perfusion, together with adjuncts to limit organ injury and increasing sophistication in open and endovascular surgery have led to a major reduction in both perioperative morbidity and mortality. In many centers, there has been a transition in mindset and surgical approach away from a purely central aortic operation focusing on the ascending aorta and a 'live to fight another day' philosophy. The current more global perspective recognizes the importance of aortic valve function, malperfusion, false lumen (FL) patency and the potential for future complex aneurysm development. The time is now right to transition into the next phase of sophistication in the management of ATAAD with the aim of achieving not only a safe acute operation, but to either entirely prevent chronic complications or to greatly simplify their management by the creation of an anatomical situation that facilitates future endovascular intervention in place of complex re-do surgery. We present our view on the evolution of surgery for ATAAD leading to our current technique of Branch First Arch replacement and Total Aortic Repair, which not only provides a safe immediate operation, but also offers the hope of a simplified future management if not a total cure for the pathology.
\end{abstract}

Keywords: Aorta; dissection; endovascular techniques

Submitted Apr 24, 2016. Accepted for publication May 04, 2016.

doi: $10.21037 /$ acs.2016.05.02

View this article at: http://dx.doi.org/10.21037/acs.2016.05.02

\section{Introduction}

Whilst the standard approach to the surgical management of acute type A aortic dissection (ATAAD) has matured in many cardiac centers around the world, the optimal surgical strategy remains a topic of intense debate. The evolution in the management of ATAAD has progressed through a number of discrete phases. Initially, there was little understanding of its physiology or natural history. Management was limited to "the patient should be kept at rest and made comfortable with narcotics" (1) and was almost universally fatal (2). Along with developments in general cardiac surgery came pioneering surgical efforts to salvage some of these patients. Early reports focused on reinforcing the dissected aorta by wrapping the diseased segment with cellophane (3) or fenestrating the septum to relieve limb ischemia (4). From this bleak survival outlook, the journey toward a definitive surgical solution and improved outcomes began.

\section{The advent of direct surgical management for ATAAD}

The second phase gave birth to direct aortic surgery for ATAAD. Paulin was one of the first to suggest that early replacement of the proximal ascending aorta may lead to a survival advantage in selected patients (3). In 1955, at the American Association for Thoracic Surgery (AATS) annual 
meeting, Debakey presented an index series with survival in 4 of 6 patients. The dissected aorta was transected, the split layers reapposed with a circumferential suture, the distal false lumen (FL) fenestrated and the aorta reanastomosed (5). Even at this early stage, the identification of the importance of adverse presentation characteristics such as aortic regurgitation (AR), hemopericardium and stroke were recognized. Despite Debakey's success, the experience of others was abysmal and led many to advocate delaying surgical intervention for days to weeks on the 'self-selected' survivors (6).

\section{Evolution of open surgical techniques}

As surgical and perfusion technology advanced, open surgery became the standard and outcomes began to improve. Surgery now focused on replacing the ascending aorta and repairing or replacing the aortic root under cross clamp and whenever possible a short interposition graft (7-9). This was still associated with mortality rates of $>25 \%$ and a high incidence of major morbidity $(10,11)$. Whilst many surgeons had become more comfortable with proximal aortic repair in the setting of ATAAD, the mantra was to not chase the dissection into the arch unless it was required as a last resort. The only method of cerebral and distal protection available was profound hypothermia. High operative morbidity, mortality, significant bleeding complications and high transfusion rates were the norm and the patient was frequently left with complex distal aortic anatomy with FL perfusion of the residual arch and persistent thoracoabdominal dissections.

The next major phase in the evolution of surgery for ATTAD was heralded by the creation of the International Registry of Acute Aortic Dissection in 1996 (12). The collaboration of experience and systematic assessment of surgical technique led to a more standardized approach to operative management of dissections. This created a greater understanding of the importance of organ protection, the need for identification and correction of malperfusion (13), the deliberate search for and resection of the primary intimal tear via an open distal anastomosis and increasing attention to sparing or replacing the aortic root when required (14-16). Driving these developments was the increasing dissatisfaction with intra-operative issues such as malperfusion and bleeding from friable residual traumatized ascending aorta associated with cross clamping (17). There was also increasing awareness of the frequent early development of arch and proximal descending aneurysms needing complex re-operations or, in untreated cases, aneurysm-related deaths associated with rapid expansion of the patent distal FL (18). In parallel, the addition of antegrade cerebral perfusion as well as improved cardiac surgical techniques and intensive care resulted in lower mortality despite longer and more complex procedures. This led to widespread adoption of the open distal anastomosis and hemiarch replacement in ATAAD (19).

\section{Current concepts in ATAAD}

This brings us to the fourth and current stage in the evolution of the management of ATAAD. We have greater understanding of the acute physiology and anatomy of dissection and in particular the importance of clinical and radiological markers of malperfusion. Advanced imaging including 4-D magnetic resonance imaging (MRI) scanning (20) has allowed a deeper appreciation of the pathogenesis of long-term complications and morbidity associated with a persistent FL. In particular, malperfusion, hitherto a marker of high mortality, is now a modifiable risk factor and one that can be predicted and treated with a demonstrable improvement in overall outcomes (21). Many of the aortic-centric institutions around the globe, including our own groups, are beginning to advocate a more proactive initial surgical strategy. Despite its reported improved outcomes, the hemiarch approach is still associated with around $50 \%$ persistent distal FL patency (22). In the acute phase this can induce distal organ malperfusion due to static or dynamic obstruction of aortic branch vessels $(23,24)$. Importantly, the manifestation of ischemia in some territories such as the bowel can be quite subtle, right until they advance to the irreversible stage (21). In the chronic phase, FL patency is associated with an increased growth rate of the distal aorta and a higher incidence of reoperation or of adverse aortic events (25-28). In addition, when only an ascending or classic hemiarch has been performed, the aneurysms that develop tend to involve the arch and proximal descending thoracic aorta and can be quite challenging to manage (25). If managed surgically, there is often need to do a complex total arch repair in the re-do median sternotomy setting. Alternatively, complete endovascular treatment usually necessitates branched/ fenestrated devices and is often difficult to achieve because of the proximity of the cerebral vessels and small working channel of the true lumen (TL) (29). In addition, the management of persistent type I or II endoleaks when stents use a proximal landing zone in native dissected arch often 
requires complex reoperative open surgery.

Despite frequent protestations to the contrary, the current safety of arch replacement in the setting of ATAAD has been borne out by a number of contemporary series including our own (30). Unfortunately, but not entirely unexpectedly, the relatively minor extra length of aortic resection gained with this approach compared to the hemiarch has not resulted in a markedly reduced FL patency. Nonetheless, there is a subtle but important difference. This lies in the dependence of arch branch flow on Dacron graft rather than dissected aorta. This greatly simplifies future stent graft interventions and virtually abolishes proximal type 1 and type 2 endoleaks due to aortic arch FL pressurization from arch intimal tears (possibly produced by the stent itself), or retrograde flow from dissected arch branches back into the arch FL.

In pursuit of more effective FL obliteration, some authors have advocated the use of standard or 'frozen' elephant trunk (FET) $(31,32)$ or intra-operative stenting of the proximal descending aorta (33). Although this does indeed reduce upper/mid thoracic FL patency (though doesn't greatly impact on lower thoracic or abdominal patency), it does not totally abolish it (34). In some cases, with continued retrograde pressurization of the FL, either through a large pre-existing distal re-entry or an iatrogenic distal edge of stent-induced tear, the FET remains poorly expanded, exacerbating TL stenosis, creating a pseudocoarctation and may even cause hemolysis. Another worrying complication is the significant risk of paraplegia, a hitherto rare complication of standard ATAAD repair $(35,36)$. Finally, zone 3 arch replacement has been associated with greater risks related to the deep distal anastomosis, which is not easily accessible, and a higher incidence of left recurrent nerve injury.

\section{Total aortic repair and the Austin approach to ATAAD}

The improved acute surgical outcomes with Branch First arch replacement, enhanced cerebral and systemic perfusion and protection adjuncts and improved understanding of the acute and chronic physiology of aortic dissection coupled with the shortcomings of the approaches aforementioned have encouraged us to develop what we believe to be a safe and effective algorithm for the repair of ATAAD. Our philosophy has evolved with the ultimate goal of low operative morbidity and mortality, whilst taking advantage of a one-stop opportunity for total aortic repair in ATAAD.
Although the technical aspects of our approach are covered in detail in the Masters Video and Art of Operative Technique article elsewhere in this issue, the key concepts in the procedure are as follows.

\section{Cannulation and management of bypass}

The choice of femoral, axillary or direct transaortic cannulation is probably less important than a high level of alertness to malperfusion and rapid establishment of guaranteed cerebral flow. We have encountered malperfusion with any of the inflow techniques. Detection includes noting flaccidity of the arch, high line pressures, falling near infrared spectroscopy (NIRS), reduced truelumen flow on transesophageal echocardiogram and divergence of arterial monitoring lines which are recorded at multiple sites. Corrective measures can be instituted including changing or adding extra inflow sources. A simple maneuver is to leave the heart partially full with continued ventilation so that cardiac ejection contributes to TL flow. The other vital component is the Branch First Technique $(30,37,38)$ where the innominate artery is debranched and reperfused via the perfusion port of the trifurcation arch with perfusion port (TAPP) graft within 10 minutes (Figure 1) ensuring rapid and direct perfusion to one of the major cerebral inflows.

\section{Branch first arch replacement}

With sequential debranching and reperfusion of the three head vessels, complete and rapid cerebral perfusion is ensured (Figure 1). Securing the source of inflow of all three head vessels from the Dacron ascending graft has a number of advantages. It protects against the need for hazardous redo sternotomy or stent grafting for residual arch dissection aneurysm by providing guaranteed cerebral inflow from the proximal ascending Dacron graft. Sufficient distance between the site of the implantation of the common stem of the trifurcation graft and the distal anastomosis can be easily built in to allow for a secure landing zone for subsequent stent grafting if needed. Finally, even though all three head vessels are debranched, the distal anastomosis can be made in the safer zone 2 (Figure $1 E, F$ ). We often encounter reservations amongst colleagues as to the difficulty of reaching and reconnecting the subclavian artery. In practice, the progression of debranching from innominate to subclavian (rather than vice versa) allows 
A

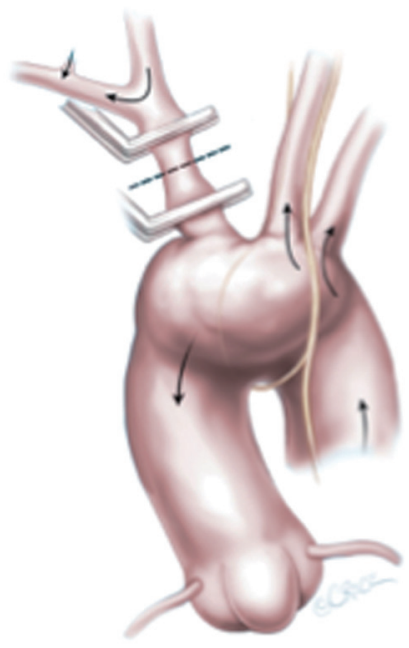

D

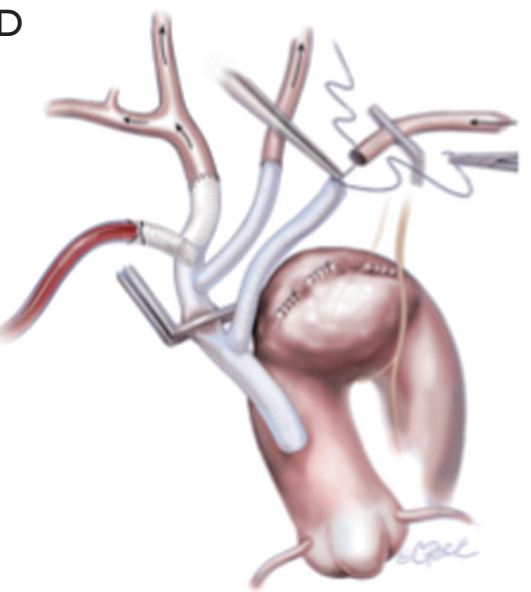

B

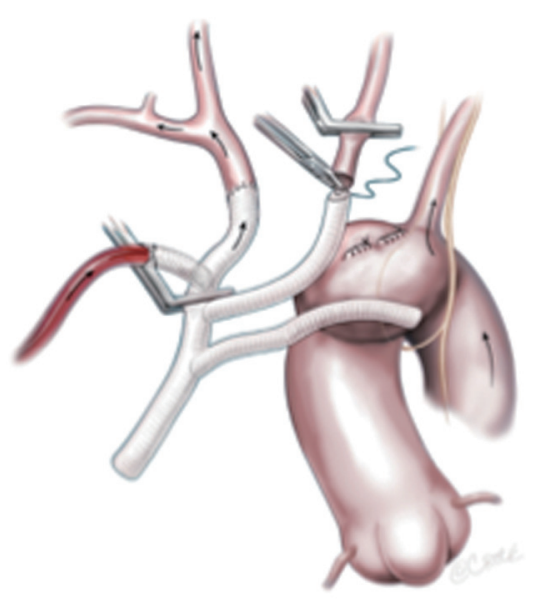

C

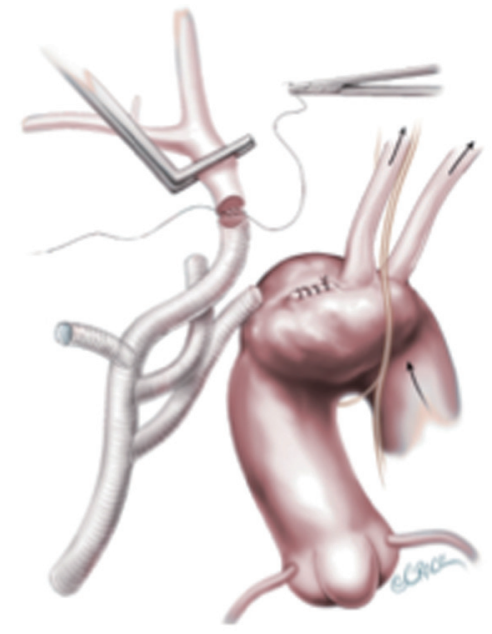

E

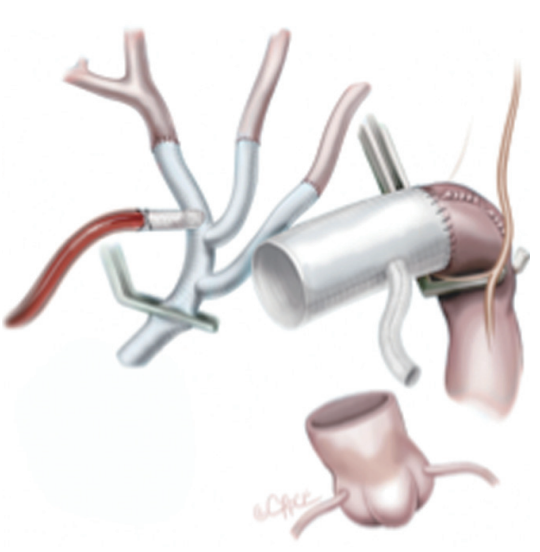

$\mathrm{F}$

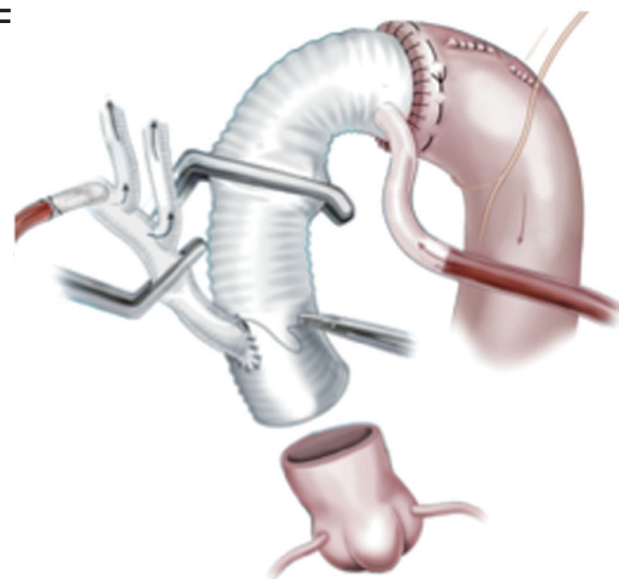

Figure 1 Sequence of branch first arch replacement. (A) The innominate artery is clamped proximal to its bifurcation and distal to its origin from the arch. Right hemispheric cerebral perfusion is maintained through the left common carotid and subclavian arteries via collateral channels; (B) the innominate stump is ligated and the anastomosis to the branched graft completed; (C) antegrade right hemispheric cerebral perfusion is resumed via a perfusion side arm. Left hemispheric cerebral perfusion during construction of the left common carotid anastomosis is maintained via the same collaterals; (D) subclavian anastomosis is completed; (E) anastomosis of the arch graft to the distal arch. Note that the distal anastomosis can be performed proximal to the left subclavian stump for ease of anastomosis and to avoid dissection in the area of the left recurrent laryngeal nerve; (F) after completion of the root anastomosis, connection of the trifurcation graft to the ascending graft proceeds without interruption of cerebral perfusion (38).

progressively more room to reach the subclavian. One can also delay the subclavian anastomosis until distal circulatory arrest, where the decompression allows much more room. Finally, if left subclavian re-implantation is felt to be too hazardous, it is easier to deal with issues related to a retained subclavian artery on the distal aorta subsequently, either with a carotid-subclavian bypass or simple single branch endovascular methods $(39,40)$.

\section{STABILIZE the thoracic-abdominal aorta}

In patients with clinical or CTA features of TL compromise, we proceed as follows. Assuming the clinical situation allows, this is done during the same hospital admission but after discharge from ICU, when the patient's neurology, circulation and renal function have returned to baseline. Covered stent grafts are deployed from the prepared Dacron landing zone to the diaphragm. The remaining thoraco- 
abdominal aorta down to the aortic bifurcation is lined with uncovered 'dissection' stent grafts (Zenith Dissection Endovascular Stent, Cook Medical Inc., Bloomington, IN, USA). These are then are forcibly balloon-dilated to effect a complete rupture of the septum between TL and FL as per the STABILIZE protocol. This ensures pressure equalization between TL and FL and creates a uniluminal aortic channel and so abolishes malperfusion and removes the chronic driving force behind FL growth. The stent affords further structural support to the weakened aorta. In our early experience with eight patients with no procedural mortality or complications, follow up CTA has demonstrated complete total aortic healing with no residual aneurysm or dissection.

\section{Conclusions}

It has been a long held belief in the treatment of ATAAD that the 'enemy of good is perfect'. The general consensus argued for a limited and simple operation which gave a predictable result and a live patient, in particular as the level of aortic experience and expertise in some centers and between surgeons in the acute situation may be limited. Nevertheless, retaining significantly diseased aorta for the sake of expedition will often set the patient up for a much more complex situation with much higher risks. Furthermore, the need for such intervention often arises in the medium rather than long term, giving the patient only a brief period of palliation. It has already been demonstrated that the combination of hemiarch resection together with better surgical and post-operative support has led to improved outcomes. The time has now arrived to adopt an approach that minimizes the acute hazards, as well as the risks of future interventions. If such interventions are required they can be achieved with minimal fuss and complications. The Branch-First arch replacement followed by thoracoabdominal 'dissection' stenting in appropriate cases is one such approach. Although the lack of expertise in the middle of the night is a valid reality this should be remedied by a combination of appropriate training of identified 'aortic specialists' in each center or, where this is not possible, in the timely diagnosis and targeted referral of ATAAD to aortic centers.

\section{Acknowledgements}

The authors thank Beth Croce for her excellent medical illustrations.

\section{Footnote}

Conflicts of Interest: The authors have no conflicts of interest to declare.

\section{References}

1. Burchell HB. Aortic dissection (dissecting hematoma; dissecting aneurysm of the aorta). Circulation 1955;12:1068-79.

2. Mccloy RM, Spittell JA Jr, Mcgoon DC. The prognosis in aortic dissection (dissecting aortic hematoma or aneurysm). Circulation 1965;31:665-9.

3. Paullin JE, James DF. Dissecting aneurysm of aorta. Postgrad Med 1948;4:291-9.

4. Benson WR, Hamilton JE, Claugus CE. Dissection of aorta: report of a case treated by fenestration procedure. Ann Surg 1957;146:111-16.

5. de bakey ME, Cooley DA, Creech O Jr. Surgical considerations of dissecting aneurysm of the aorta. Ann Surg 1955;142:586-610; discussion, 611-2.

6. Parker FB, Neville JF Jr, Hanson EL, et al. Management of acute aortic dissection. Ann Thorac Surg 1975;19:436-42.

7. Matloff JM, Matloff DB. Acute aortic dissection due to cystic necrosis. Four cases of emergency replacement of the ascending aorta withsurvival. Arch Surg 1970;101:8-13.

8. Cohn LH, Fogarty TJ, Daily PO, et al. Successful repair of subcoronary ascending aortic dissection. Ann Thorac Surg 1972;13:60-2.

9. Najafi H, Dye WS, Javid H, et al. Acute aortic regurgitation secondary to aortic dissection. Surgical management without valve replacement. Ann Thorac Surg 1972;14:474-82.

10. Seybold-Epting W, Meyer J, Hallman GL, et al. Surgical treatment of acute dissecting aneurysm of the ascending aorta. J Cardiovasc Surg (Torino) 1977;18:43-8.

11. Wolfe WG, Oldham HN, Rankin JS, et al. Surgical treatment of acute ascending aortic dissection. Ann Surg 1983;197:738-42.

12. Hagan PG, Nienaber CA, Isselbacher EM, et al. The International Registry of Acute Aortic Dissection (IRAD): new insights into an old disease. JAMA 2000;283:897-903.

13. Estrera AL, Garami Z, Miller CC 3rd, et al. Cerebral monitoring with transcranial Doppler ultrasonography improves neurologic outcome during repairs of acute type A aortic dissection. J Thorac Cardiovasc Surg 2005;129:277-85.

14. Bavaria JE, Brinster DR, Gorman RC, et al. Advances in the treatment of acute type A dissection: an integrated approach. 
Ann Thorac Surg 2002;74:S1848-52; discussion S1857-63.

15. Bavaria JE, Pochettino A, Brinster DR, et al. New paradigms and improved results for the surgical treatment of acute type A dissection. Ann Surg 2001;234:336-42; discussion 342-3.

16. Rylski B, Milewski RK, Bavaria JE, et al. Long-term results of aggressive hemiarch replacement in 534 patients with type A aortic dissection. J Thorac Cardiovasc Surg 2014;148:2981-5.

17. David TE, Armstrong S, Ivanov J, et al. Surgery for acute type A aortic dissection. Ann Thorac Surg 1999;67:19992001; discussion 2014-9.

18. Evangelista A, Salas A, Ribera A, et al. Long-term outcome of aortic dissection with patent false lumen: predictive role of entry tear size and location. Circulation 2012;125:3133-41.

19. Sakamoto T, Yoshida T, Sugano T, et al. Simplified technique for hemi-arch replacement during open distal anastomosis: the "calla" method. Ann Thorac Surg 1996;61:1021-3.

20. Clough RE, Waltham M, Giese D, et al. A new imaging method for assessment of aortic dissection using fourdimensional phase contrast magnetic resonance imaging. J Vasc Surg 2012;55:914-23.

21. Perera NK, Galvin SD, Seevanayagam S, et al. Optimal management of acute type A aortic dissection with mesenteric malperfusion. Interact Cardiovasc Thorac Surg 2014;19:290-4.

22. Sakaguchi G, Komiya T, Tamura N, et al. Patency of distal false lumen in acute dissection: extent of resection and prognosis. Interact Cardiovasc Thorac Surg 2007;6:204-7.

23. Pacini D, Leone A, Belotti LM, et al. Acute type A aortic dissection: significance of multiorgan malperfusion. Eur J Cardiothorac Surg 2013;43:820-6.

24. Girdauskas E, Kuntze T, Borger MA, et al. Surgical risk of preoperative malperfusion in acute type A aortic dissection. J Thorac Cardiovasc Surg 2009;138:1363-9.

25. Immer FF, Krähenbühl E, Hagen U, et al. Large area of the false lumen favors secondary dilatation of the aorta after acute type A aortic dissection. Circulation 2005;112:I249-52.

26. Fattori R, Bacchi-Reggiani L, Bertaccini P, et al. Evolution of aortic dissection after surgical repair. Am J Cardiol 2000;86:868-72.

27. Barron DJ, Livesey SA, Brown IW, et al. Twenty-year follow-up of acute type a dissection: the incidence and extent of distal aortic disease using magnetic resonance imaging. J Card Surg 1997;12:147-59.

28. Park KH, Lim C, Choi JH, et al. Midterm change of descending aortic false lumen after repair of acute type I dissection. Ann Thorac Surg 2009;87:103-8.

29. Swee W, Dake MD. Endovascular management of thoracic dissections. Circulation 2008;117:1460-73.
30. Matalanis G, Perera NK, Galvin SD. Aortic arch replacement without circulatory arrest or deep hypothermia: the "branch-first" technique. J Thorac Cardiovasc Surg 2015;149:S76-82.

31. Leontyev S, Tsagakis K, Pacini D, et al. Impact of clinical factors and surgical techniques on early outcome of patients treated with frozen elephant trunk technique by using EVITA open stent-graft: results of a multicentre study. Eur J Cardiothorac Surg 2016;49:660-6.

32. Ma WG, Zhang W, Wang LF, et al. Type A aortic dissection with arch entry tear: Surgical experience in 104 patients over a 12-year period. J Thorac Cardiovasc Surg 2016;151:1581-92.

33. Pochettino A, Brinkman WT, Moeller P, et al. Antegrade thoracic stent grafting during repair of acute DeBakey I dissection prevents development of thoracoabdominal aortic aneurysms. Ann Thorac Surg 2009;88:482-9; discussion 489-90.

34. Di Eusanio M, Castrovinci S, Tian DH, et al. Antegrade stenting of the descending thoracic aorta during DeBakey type 1 acute aortic dissection repair. Eur J Cardiothorac Surg 2014;45:967-75.

35. Di Bartolomeo R, Pantaleo A, Berretta P, et al. Frozen elephant trunk surgery in acute aortic dissection. J Thorac Cardiovasc Surg 2015;149:S105-9.

36. Haldenwang PL, Prochnow N, Baumann A, et al. Spinal cord ischemia after selective cerebral perfusion in a porcine "frozen elephant trunk" simulation model. Ann Thorac Surg 2015;99:1624-31.

37. Galvin SD, Matalanis G. Continuous perfusion "Branchfirst" aortic arch replacement: a technical perspective. Ann Cardiothorac Surg 2013;2:229-34.

38. Matalanis G, Galvin SD. "Branch-first" continuous perfusion aortic arch replacement and its role in intraoperative cerebral protection. Ann Cardiothorac Surg 2013;2:194-201.

39. Madenci AL, Ozaki CK, Belkin M, et al. Carotidsubclavian bypass and subclavian-carotid transposition in the thoracic endovascular aortic repair era. J Vasc Surg 2013;57:1275-1282.e2.

40. Kuratani T. Best surgical option for arch extension of type B dissection: the endovascular approach. Ann Cardiothorac Surg 2014;3:292-9.

Cite this article as: Matalanis G, Perera NK, Galvin SD. Total aortic repair: the new paradigm in the treatment of acute type A aortic dissection. Ann Cardiothorac Surg 2016;5(3):216-221. doi: 10.21037/acs.2016.05.02 